\title{
Path Constitution Analysis: A Methodology for Understanding Path Dependence and Path Creation
}

\author{
Jörg Sydow, Department of Management, Freie Universität Berlin, Germany, E-Mail: joerg.sydow@fu-berlin.de \\ Arnold Windeler, Institute of Sociology, Technische Universität Berlin, Germany, E-Mail: arnold.windeler@tu-berlin.de \\ Gordon Müller-Seitz, Department of Management, Freie Universität Berlin, Germany, E-Mail: gordon.mueller-seitz@fu-berlin.de. \\ Knut Lange, Surrey Business School, University of Surrey, United Kingdom, E-Mail: k.lange@surrey.ac.uk
}

\begin{abstract}
Although an increasing number of studies of technological, institutional and organizational change refer to the concepts of path dependence and path creation, few attempts have been made to consider these concepts explicitly in their methodological accounts. This paper addresses this gap and contributes to the literature by developing a comprehensive methodology that originates from the concepts of path dependence and path creation - path constitution analysis (PCA) - and allows for the integration of multi-actor constellations on multiple levels of analysis within a process perspective. Based upon a longitudinal case study in the field of semiconductors, we illustrate PCA 'in action' as a template for other researchers and critically examine its adequacy. We conclude with implications for further path-oriented inquiries.
\end{abstract}

JEL-classification: D23, D84, L14, L24, L63

Keywords: qualitative methodology; path dependence; path creation; path constitution analysis; multilevel approach; process data

Manuscript received June 29, 2011, accepted by Peter Walgenbach (Management) July 10, 2012.

\section{$1 \quad$ Introduction}

There is an increasing interest in studies in the field of technology and innovation management that are informed by path concepts (e.g., Ansari and Garud 2009). This research can be traced back to David's (1985) and Arthur's (1989) notion of path dependence, which emphasizes the importance of self-reinforcing processes that are triggered by (small) events leading to a (potential) lock-in and occurring mainly behind the backs of agents. In contrast, the more recent approach of Garud and Karnøe (2001) calls for a more explicit conceptualization of (multiple) actor(s) who are thought of as intentionally influencing the path's trajectory. Though both approaches are obviously related to one another theoretically, they are usually dealt with separately. What is more, previous studies that tried to integrate these different views at least to some extent have turned to the organizational and/or institutional realm (e.g., Sydow, Schreyögg, and Koch 2009) and thus improved our understanding of paths in settings other than the technological. Nevertheless, there are hardly any studies devoted mainly to the question of how such paths can be analyzed empirically (see for exceptions Schubert and Windeler 2007; Vergne and Durand 2010; Koch 2011).

Given this observation, for this paper we employ the term path constitution in order to refer to the concepts of path dependence as well as path creation, embedding these two perspectives into the more general idea of social constitution (Giddens 1984) - hence, the notion of path constitution (Windeler 2003 as well as Sydow, Windeler, Schubert, and Möllering 2012 for a detailed ac- 
count of structuration theory in relation to path conceptions). This allows us to integrate the two perspectives constructively, which have been used by and large separately up until now. In addition, we propose a multi-level process analysis of technological, institutional and/or organizational paths which integrates an institutional with a strategic analysis. While the former concentrates on the reproduction of structural properties by individual or collective agents, the latter focuses "upon modes in which agents draw upon structural properties in the constitution of social relations" (Giddens 1984: 88, also 288-347).

Although the studies of path dependence as well as of path creation typically make use of historysensitive and mostly qualitative process-oriented analyses (Bennett and Elman 2006), much like methodological approaches to technological or organizational change in general (e.g., Street and Gallupe 2009), they have not, at least so far, produced a more detailed research methodology that is able to capture the process features emphasized by previous research. Rather, the respective studies have applied specific methods such as discourse analysis or simulation (e.g., Hess, Kleinschmitt, Theuvsen, von Cramon-Taubadel, and Zschache 2010 and Koch, Eisend, and Petermann 2009, respectively). Therefore, we propose not only a multi-level process methodology but one that provides a more elaborate procedure deeply anchored in the theory of technological, institutional and/or organizational path dependence/ creation.

Against this background and in line with recent calls to pay more attention (also) to qualitative methodological approaches (Aguinis, Pierce, Bosco, and Muslin 2009; Pratt 2008), we develop a processual, fine-grained methodology that is informed by structuration theory and tailored towards the specific phenomenon under scrutiny; in our case, applied to the field of technology and innovation management in which, obviously, both organizations and other institutions matter. With this in mind, this paper pursues two objectives: first, we aim at introducing a novel and comprehensive methodology, path constitution analysis or PCA for short, by building upon prior works on path dependence and path creation. Bearing in mind the fact that we relate to Giddens' theory of structuration (1984; also again Windeler 2003), it appears necessary to design the PCA in an inter- pretative, social constructivist manner (Lincoln and Guba 1985) without, on the one hand, sticking to methodological individualism or simply applying an institutional or structural analysis on the other (for a parallel claim, see Jepperson and Meyer 2011). Second, we offer a detailed and processual procedure that is intended to serve as a guiding template for other researchers regarding how to utilize this comprehensive and nevertheless operable methodology. Following the exposition of this methodology, we present the PCA 'in action', elucidating its applicability by reverting to a longitudinal case study using processual data. To this aim, we examine our own empirical work in the semiconductor manufacturing industry with regard to the development of a technological path by multiple organizations, and critically reflect upon the adequacy of the PCA.

The structure of this paper is as follows: in the next section we offer a definition of a path and delineate its constituent features, which are consequently essential to a PCA. In addition, we give a short overview of research methods that have been used before to study technological, institutional or organizational paths. This allows us to position our PCA in relation to former approaches. Thereafter, we introduce the setting for our exploratory research, the semiconductor manufacturing tool industry, and explain our methodology in detail. Subsequently, we illustrate the PCA 'in action' with regard to the collaborative development of a complex system technology for manufacturing semiconductors - that is, Extreme Ultraviolet Lithography (EUVL). Thereby, we constantly re-examine our findings critically, elucidating the possibilities and limitations of utilizing the PCA. We conclude with a summary and an outlook for future research endeavors in the field of path-dependent processes.

\section{PCA as a Methodology}

As a first step, we set out the overarching development of path concepts from the notion of path dependence to path creation, and then present our conception of path constitution, which is informed by structuration theory (Giddens 1984) and allows the integration of both research strands on path development. Each research strand is presented with respect to its theoretical 
contribution as well as the methodological approaches and methods adopted. In a second step - one theoretically informed by the concept of path constitution -, we define paths and offer indicators for their measurement. Methodology is conceived here a generic framework that complements epistemology and ontology and helps to detect, analyze, interpret, and systemize processes of social praxis (Cohen 1989; Giddens 1989). Typically, such a methodology helps to apply theory - in this case structuration theory - in empirical research as a "sensitizing device" (Giddens 1984) that obviously relies on a more or less diverse set of specific methods.

\subsection{From Path Dependence and Path Creation to Path Constitution}

\subsubsection{Path Dependence}

The analysis of first technological - and later institutional - path dependence started out from a critique of neoclassical economics that was grounded in evolutionary and institutional economics (Arthur 1989; David 1985; North 1990). Whereas orthodox economics assumes the primacy of optimal solutions in terms of efficiency, the theory of path dependence pays attention to the impact of past events, often captured in the catch phrase "history matters". However, the concept of path dependence actually goes far beyond mere "past-dependence" (Antonelli 1997), acknowledging the importance of self-reinforcing processes that are triggered by one or more, often "small" events and drive the development of a path (Arthur 1989, 1994; David 1985). Although the primary conditions of any path-dependent process are contingent, the respective events represent initial conditions that, by triggering a selfreinforcing process, have an enduring impact upon the course of the path's future trajectory. However, the impact is anything but clear at the start of the process. This aspect points to the fact that paths are non-ergodic (Arthur 1994; David 2001, 2007); while different outcomes are possible at the beginning, the range of options narrows down over time in the face of self-reinforcing processes, in the form of "increasing returns" (Arthur 1989, 1994; David 1985), for instance, which determine the outcome of the process and will most likely lead into a technological, institutional or organizational lock-in.
Concerning the chosen methodologies, the still relatively few studies devoted to path dependence revert to a wide range of approaches. This is not surprising, given the broad field of application of path dependence/creation thought, covering not only technologies but also increasingly organizations and other types of institutions. Nevertheless, the most prominent methodological approach by far is the case-study design (Yin 1981, 2009), which almost always uses lots of historical data, qualitative and/or quantitative. Take, for instance, the seminal study by David (1985) of the technological path dependence of the QWERTY keyboard and, much more recently, the study of organizational path dependence by Koch (2011), who analyzed the strategic development of media corporations in the market of national dailies that produce high-quality newspapers in Germany. Another example is the study of behavioral lockins in the U.S. health industry and the U.S. beer market by Barnes, Gartland, and Stack (2004).

However, other than case studies are common too. An experimental design is chosen, for instance, by Koch, Eisend, and Petermann (2009), who investigated the relationship between environmental complexity and path dependence in sequential decision-making processes. Petermann (2010) used agent-based simulation to study the role of hierarchy in organizational path dependence. Other approaches, among them innovation biographies, and real ethnography, especially in combination with quantitative methodologies such as social network analysis or the analysis of time-series data (as mixed methods), still await use in research projects on technological, institutional or organizational paths.

What is more, a debate about the appropriate methodology has regained momentum only recently, when Vergne and Durand (2010) not only called for more robust research designs, but questioned the value of real-time data collection and process-oriented case studies. In effect, they advocated that path dependence research should focus exclusively on computer-based simulations, counterfactual investigations, and experimental designs to actually "test" path dependence and enable inquiries into causal relationships. In response to their assessment, Garud, Kumaraswamy, and Karnøe (2010) argued for the continuation of case-study research, using more qualitative and fine-grained ethnographic meth- 
ods of data gathering and analysis. Even more recently, Dobusch and Kapeller (2013), continuing this debate, asked for a general methodological openness and a combination of different research methods, quantitative as well as qualitative.

PCA, while principally open to a qualitative as much as a quantitative or even a multi-method approach (Tashakkori and Teddlie 2003; Creswell and Clark 2007), is certainly closer to the position of these latter authors than to that of Vergne and Durand. In addition, it is important to note that PCA is distinctively different from grounded theory (Glaser and Strauss 1967; Suddaby 2006) because it builds on explicit theorizing, in this case about path constitution, integrating path dependence and creation research with the help of a structurationist framework. In consequence, the constitutive features and potential indicators of paths, at least at this stage of the development of PCA, are derived from theory, not from empirical data.

\subsubsection{Path Creation}

Recently and importantly, Garud and Karnøe (2001) complemented the notion of path dependence by introducing the concept of path creation. The main difference between this concept and path dependence concerns the emphasis upon agency and collectivities of multiple, competent individual and/or organizational actors in particular, who coordinate their activities with each other. Therefore, not only external shocks - as conceived by David (2001) and many other path researchers - lead to deviations from existing technological, institutional or organizational paths, but also mindful deviations by collectivities of actors (Garud and Karnøe 2001: 6) - even though they may not be proficient enough to initiate or control the deviation entirely.

Methodological approaches studying path creation to date predominantly revert exclusively to case studies (Yin 1981, 2009). For instance, Garud and Karnøe (2003) discussed the role of distributed and embedded agency in technology entrepreneurship related to the wind turbine industry in the U.S. and Denmark. Almost all cases Garud and Karnøe (2001) collected for their influential edited volume on path creation use such a case-study approach, although they are not necessarily confined to qualitative data.

\subsubsection{Path Constitution}

The concept of path constitution attempts to integrate the concepts of path dependence and creation. Instead of "mixing ontologies" (Garud, Kumaraswamy, and Karnøe 2010), this concept offers a constructivist understanding in which path dependence and path creation are only two possible ways to build and transform a path in time and space; others are intentional path defense or extension, unintended path dissolution, or breaking a path without creating a new one (Meyer and Schubert 2007; Sydow, Windeler, Schubert, and Möllering 2012). In line with received path dependence theory, our understanding of technological, institutional or organizational paths always implies a certain degree of path dependence in the sense that path processes, even if they are intentionally created, show a kind of irreversibility, momentum, and possibly lock-in.

The central idea of path constitution is the call for a theoretical understanding which acknowledges the recent constructivist turn in path research (e.g., Garud and Karnøe 2001; Windeler 2003; Sydow, Schreyögg, and Koch 2009; Sydow, Windeler, Schubert, and Möllering 2012; Sydow, Lerch, and Staber 2010) and applies more recent concepts of path creation and the like without losing its capabilities to explain path-dependent processes. Structuration theory (Giddens 1984), which we propose as one of the possible candidates for this endeavor (another candidate might be, for instance, evolution theory; Dosi 1982; Dosi and Ortenigo 1988), underpins the following definition and conceptualization, calls for an integration of institutional and strategic analyses, and delivers a sophisticated theoretical lens for data analysis and interpretation. Of particular importance is in this regard the idea that paths represent reflexive and non-reflexive institutionalized event-flows (Windeler 2003) that are characterized by self-reinforcing processes, which result in somewhat more than a recursive stabilization over time.

\subsection{Definition and Constitutive Features of a Path}

Bearing the concept of path constitution in mind, we define a path based upon the path concepts introduced (Arthur 1989, 1994; David 1985; Garud and Karnøe 2001) as being a course of events interrelated on different levels of analysis, such as 


\section{Table 1: Constitutive Features and Potential Indicators of Paths}

\begin{tabular}{|c|c|c|}
\hline Constitutive feature & Definition & Indicators \\
\hline Level interrelatedness & $\begin{array}{l}\text { A focal level of analysis that needs to be } \\
\text { conceptualized in relation to surround- } \\
\text { ing levels of analyses that are more mi- } \\
\text { cro and macro. }\end{array}$ & $\begin{array}{l}\text { Actors and/or observers relate their } \\
\text { activities (1) recurrently, (2) intensively, } \\
\text { (3) and to an important extent not only } \\
\text { to a focal, but at the same time to more } \\
\text { micro and macro levels of analysis. }\end{array}$ \\
\hline Triggering event & $\begin{array}{l}\text { Incident that potentially induces the } \\
\text { current and/or future trajectory of a } \\
\text { path. }\end{array}$ & $\begin{array}{l}\text { Actors and/or observers assess an inci- } \\
\text { dent as being (1) decisive, (2) initiating } \\
\text { self-reinforcing processes for an option's } \\
\text { likelihood to be prevalent in the future ... }\end{array}$ \\
\hline Non-ergodic process & $\begin{array}{l}\text { Course of simultaneous and/or sequen- } \\
\text { tial events that lead to an outcome, } \\
\text { which is not automatically determined } \\
\text { from the onset but is not arbitrarily, } \\
\text { either. }\end{array}$ & $\begin{array}{l}\text { From the onset, (1) options of equal } \\
\text { potential are (2) narrowed down to (3) a } \\
\text { final solution. }\end{array}$ \\
\hline Self-reinforcing processes & $\begin{array}{l}\text { Course of interlocking simultaneous } \\
\text { and/or sequential events that are pro- } \\
\text { gressively aligned to each other, thereby } \\
\text { fostering the overall course of a path in } \\
\text { an overall direction and potentially lead- } \\
\text { ing to a momentum; in this connection, } \\
\text { certain initial conditions are connected } \\
\text { with certain results. }\end{array}$ & $\begin{array}{l}\text { Over time, (1) (interorganizational) } \\
\text { overarching institutions that serve to } \\
\text { formulate and pursue joint objectives are } \\
\text { established, (2), the design and usage of } \\
\text { complementary management systems } \\
\text { with regard to organizational aspects, } \\
\text { and operations, (3) learning effects rein- } \\
\text { force ... }\end{array}$ \\
\hline Lock-in & $\begin{array}{l}\text { Situation or outcome where the trajecto- } \\
\text { ry of a path becomes confined to a single } \\
\text { solution that does not need to be effi- } \\
\text { cient. }\end{array}$ & $\begin{array}{l}\text { (1) investments are stable or increase } \\
\text { with regard to the prevailing option, (2) } \\
\text { investments in alternatives are reduced, } \\
\text { (3) alternative options are considered to } \\
\text { be niches ... }\end{array}$ \\
\hline Multiple actors & $\begin{array}{l}\text { Constellations of individual or collective } \\
\text { agents. }\end{array}$ & $\begin{array}{l}\text { (1) number of actors (more than two), } \\
\text { (2) properties of actors, ( } 3 \text { ) actors bound } \\
\text { together by sets of relations ... }\end{array}$ \\
\hline
\end{tabular}

a single organization or an organizational or technological field, and in which one of the available technological, institutional or organizational options gains momentum in time-space, but cannot automatically be determined from the onset. This non-ergodic development is triggered by certain actions or events, and driven by specific self-reinforcing mechanisms that not only cause the momentum, but might lead the whole process into a lock-in that is, at least from a strategic perspective, inefficient (Sydow, Schreyögg, and Koch 2009).

It remains an empirical question as to whether the path is predominantly constituted by processes beyond the reach and consciousness of knowledgeable actors (i.e. 'behind their backs') or by processes that are designed or at least shaped by powerful collectivities of actors as advocated by Garud and Karnøe (2001) and their notion of "path creation". In any case, it makes sense to speak of a path only in those instances where competing options existed and the later 'solution' was not foreseeable at the beginning of a path and where the development culminated in a process of narrowing down to only one option.

Given this definition of a path, a PCA requires the development of a precise understanding of (a) level interrelatedness, (b) triggering events, (c) non-ergodic processes, (d) self-reinforcing processes, (e) lock-in, and (f) multiple actors who intentionally or unintentionally (re-)produce the path in time-space (see also Table 1). In what follows we set out our detailed understanding of these constitutive features, each followed by a set of potential indicators that need to be sampled purposefully, as the approach is path conceptually informed:

(a) Closely connected to the notion of social embeddedness (Granovetter 1985) is our understanding of level interrelatedness, which refers to 
the fact that a certain path can only be observed when it is put into perspective with regard to the surrounding - i.e. contextual - levels of analysis (Ragin 2006). Level interrelatedness, though, is produced and reproduced by knowledgeable and powerful agents who refer in their activities recursively, but not necessarily reflexively to contextual or institutional features in their strategic behavior (Windeler 2003). This so-called 'focus level' of analysis relates to the level on which the path under scrutiny develops, no matter whether this is of a technological, institutional or organizational nature, or - as in the case of technologyintensive firms (Valorinta, Schildt, and Lamberg 2011) or regional clusters (Sydow, Lerch, and Staber 2010) - a mixture of these. By contrast, the 'surrounding levels' of analysis are those that are relevant for understanding the development of the focal path because of possible interference from processes from 'above' (termed 'upper boundary level') as well as from 'below' (entitled 'lower boundary level') the focal level of analysis. The identification of potential indicators for level interrelatedness emanates from the empirical or conceptual interest of the researcher. Hence, it is advisable to start from the focal level of analysis that depends upon the research objective. Subsequently, the lower and upper boundary levels of analysis (at least) ought to be taken into consideration as well. In the case of regional clusters or strategic alliances and networks, this would be the field and the organizational levels, respectively (Windeler and Sydow 2001 for an example in the media industry).

(b) For our purposes, in the eyes of the relevant actors or observers at least one triggering event initiates a path process. It is worth noting that the relevant actors and/or observers might not perceive the single or multiple events while it or they are happening 'behind their backs'. However, it is less for this reason that such path-triggering events are usually considered "small" (David 1985), but in relation to their actual long-term effects. However, in retrospect, such events, that trigger and transform the trajectory of the path, in the long run (in a related vein: Pierson 2004) may turn out to be neither small nor innocent after all. Think, for instance, of the strategic move of JVC and other manufacturers of video players to sign a contract with leading Hollywood studios in order to secure content in a format (VHS) that fitted their machines (Cusumano, Mylonadis, and Rosenbloom 1992).

Indicators for triggering events must be perceived as being decisive for initiating the respective path at what is often called a "critical juncture" (Collier and Collier 1991). The assessment of the relevance of the particular event stems either from actors who are engaged with the path (i.e. when they mention these events by themselves) or from outside observers. The latter case is important, because the triggering event(s) may emerge 'behind the backs of the actors', which is why outside observers (e.g., consultants, market analysts or researchers) are deemed to add valuable insights and shed different lights upon the expost reconstruction of the respective paths. Therefore, the data need to be collected from multiple sources, allowing for triangulation (Jick 1979). Closely connected to this demand is the assumption that causality (to some extent) between the event and the path's trajectory can actually be established (Abbott 1992, 1997; Mayntz 2004).

(c) Non-ergodicity is a process characteristic that implies a course of simultaneous and/or sequential events culminating in an outcome that is not automatically determined from the onset, but not arbitrarily either (Arthur 1994; David 2001, 2007). While different outcomes are possible at the beginning the range of options narrows - or is narrowed - down over time. Consider again, as an example, the case of VHS versus Beta (Cusumano, Mylonadis, and Rosenbloom 1992) versus Video 2000 (in some European countries).

Indicators for non-ergodic processes can be gathered retrospectively and/or in real-time. As a first step, the process can be captured by identifying the relevant options that have or had more or less equal potential at the beginning. If a path process is at work, one would expect the number of finite options to be reduced substantially over time (in the case of video recorders, in the later years, from 2 or 3 to 1). However, it is not enough if a few options cease to exist but the overall number of options remains very high. In the final phase of a path process, a single final solution prevails (e.g., VHS). Although other options might still be available, they represent solutions for niches at best, whereas the prevailing option dominates over already-terminated or stillexisting options. 
(d) With regard to the development of paths, we conceive self-reinforcing processes as being characterized by positive feedback which drives the course of a path into an overall direction that is already being pursued (Arthur 1989; David 1985; Mahoney 2001). This mechanism, which is without doubt at the heart of the theory of path dependence and comprises coordination and complementarity as well as learning effects and adaptive expectations (Sydow, Schreyögg, and Koch 2009), is embedded in a specific multi-level context with which it interacts (Koch 2011). In consequence, both aspects result in processes that generate (for observers or relevant actors) an overall direction, supported by simultaneous and/or sequential actions that are progressively aligned to each other and give the process momentum, accompanied by an increasing degree of rigidity, which might culminate in a lock-in.

Potential candidates for indicators of selfreinforcing processes need to be ascertained on the social dimensions of social (re-)production, i.e. signification, domination, and legitimation (Giddens 1984). This means the indicators must be portrayed against the background of both the commonly shared cognitive and normative assumptions of the actors and of their ways of dealing with material and immaterial resources that lead to rigidity once a path has been established (Windeler 2003; Schubert and Windeler 2007; Koch 2011; Sydow, Windeler, Schubert, and Möllering 2012). Shared cognitive and normative assumptions might lead - among others - to coordination effects and complementarity effects already mentioned (see also Beyer 2010). Coordination effects refer to the efficiency of human interactions or organizational operations/procedures. Possible indicators for such coordination effects are the establishment of overarching institutions that serve to formulate and pursue joint objectives. Complementarity effects, by contrast, relate to synergies that are derived from drawing upon a bundle of resources, rules or practices rather than making use of each element of the bundle independently (Pierson 2000). Possible indicators for such effects are the design and usage of complementary technologies (like VHS cassettes and Hollywood movies) or management systems with regard to organizational aspects (e.g., the design of membership in an interorganizational arrangement), and operations (e.g., the possibility to draw upon joint resources - such as facilities - provided by the interorganizational arrangement; Windeler and Sydow 2001). These effects are also responsible for building momentum for some alternatives while detracting it from others (Page 2006; Vergne and Durand 2010).

(e) A lock-in denotes a situation or outcome whereby the trajectory of a path becomes confined to one single solution that, even in the face of more efficient alternatives, agents have to follow by and large. Such a lock-in may be of a predominantly cognitive, normative or resourcebased nature (Windeler 2003; Sydow, Schreyögg, and Koch 2009). Being locked-in implies that subsequent developments are predictable, i.e. predetermined as long as the lock-in exists. Hereby, it is essential that a lock-in is not an inevitable consequence from the onset, but only a likely result of the self-reinforcing processes at work. Moreover, given the principal ability of agents to "act otherwise" (Giddens 1984), we assume from a constructivist perspective that a lock-in is never final, particularly not in the institutional and organizational realm. Even in the case of technology, the dominance of the QWERTY keyboard for data entry may cease to exist in the face of spreading voice recognition (as the VHS technology did in the face of DVDs and, more recently, BDs).

Indicators for a lock-in might be when the assumption is taken for granted that no alternative option appears to be available for some period of time. Moreover, alternative and formerly competing options are assessed increasingly by the relevant actors/observers as being of minor importance or are simply - at best - referred to as niches. A further indicator could be that investments into a prevailing, seemingly single-best solution are, without discussion, signified and evaluated as appropriate and/or receive unquestioned a stable or even increasing amount of resources. Another indicator could be that the structuring of interorganizational or personal relationships becomes in the same vein taken for granted and a natural target of prolongation. As a result, in the extreme form only a single option remains or appears legitimate.

(f) Accurate identification is required of the multiple types of actors (e.g., depending upon different forms of markets, such as those for consumer or industry goods) and their influence on each 
other as well as upon the development of the path. For the PCA, an actor can comprise any individual person or any collectivity such as an organization or even an interorganizational network.

A potential indicator for multiple actors is the number of relevant actors or actor constellations, often usefully qualified by the type and size of organization or other attributes. At the very least, two actors must have an interest in a certain path in order to allow for a kind of 'comparative process analysis' as it was the case in our study of the next generation of lithography technology for manufacturing semiconductors.

\section{$3 \quad$ Research Setting and Methods}

\subsection{Research Setting}

Our study set in the semiconductor manufacturing industry concentrates upon the creation of a technological path by multiple organizations through mindful deviation from an established one. However, as we will show, it is quite certain that the technological innovation aimed at by the actors will, at least if they are successful, actually constitute a (new) technological path, i.e. involve path dependence. For our study, we selected the semiconductor manufacturing industry, as the dominant optical lithography, without doubt, reflects a path-dependent technology that is vitally important for all highly developed market economies (Langlois and Steinmueller 1999).

The selection, development and introduction of a completely new procedure to manufacture computer chips - which is currently a key issue in this industry - provide an excellent opportunity for demonstrating a PCA 'in action'. This manufacturing process as it exists today has been plagued by path dependence for decades. At present it is regarded by the actors themselves as a case for possible path creation - that is, the actors are convinced that they have to opt for only one particular new technology from a range of alternatives, because the promotion of more than one technology would be far too costly. And if the selected technology is finally introduced, actors will have to stick to it for at least 15 years, probably even longer (see also Linden, Mowery, and Ziedonis 2000).

\subsection{Data Collection}

We opted for the PCA as a qualitative approach for several reasons, though a mixed-method approach may be preferable in the end. First, the interorganizational creation of a technological path is still fairly uncharted territory (for an exception: Garud and Karnøe 2001). Hence, it comes as no surprise that all the studies of path creation so far have used such an approach and used quantitative data only as a byproduct (for an exception: Baum and Silverman 2001). Second, in the analysis of path constitution processes, 'how' and 'why' questions are predominant. In such circumstances, qualitative case studies are recommended (Edmondson and McManus 2007; Yin 2009). However, in line with recent calls (Aguinis, Pierce, Bosco, and Muslin 2009; Bitektine 2008, Piekkari, Welch, and Paavilanien 2009), our approach differs from classical casestudy research; we include - e.g., in contrast to Yin's (2009) focus upon contemporary phenomena (Gibbert, Ruigrok, and Wicki 2008) - historical and real-time analyses that are theoretically informed; and we thereby tailored towards the specific characteristics of our understanding of path concepts (and not vice versa). Third, in order to investigate processes of path constitution, a longitudinal and at the same time explorative inquiry is necessary. Fourth, qualitative methods such as in-depth case studies using, among others, semi-structured interviews and archival data (e.g., press releases) allow us to find out how actors and incidents on different levels are related to each other ex post. This holds particularly true for the analysis of paths, as they are socially constructed phenomena that need to be approached by means of an interpretative research design (Lincoln and Guba 1985). As a path cannot be measured objectively, we deliberately attempt to disclose the respondents' personal points of view, striving for data 'richness' in the course of exploring the phenomena under study: paths in this case.

Subsequent to pre-studies in optical technologies that sensitized us to the challenges that the semiconductor industry is facing, our study is part of a completed (2003-2010) and an ongoing project (since 2010) into the way complex system technologies are extended and created in the semiconductor industry in search of a novel manufacturing technology, so-called next-generation 
Table 2: Range of Documents

\begin{tabular}{ll} 
Document type & Documents analyzed \\
\hline NTRS documents & NTRS Editions (1992, 1994, 1997) \\
\hline ITRS documents & ITRS Editions (biannually since its inception in 1999) \\
& ITRS Updates (biannually since its inception in 1998)
\end{tabular}

\begin{tabular}{l}
$\begin{array}{l}\text { Documents issued by organiza- } \\
\text { tions }\end{array}$ \\
$\begin{array}{l}\text { Annual reports and press releases from the websites of relevant companies (e.g. Intel } \\
\text { and IBM), industry associations (e.g. Semiconductor Industry Association) and consor- } \\
\text { tia (e.g. SEMATECH) } \\
\text { Hewlett Packard Journal / Digital Technical Journal } \\
\text { IBM Journal of Research and Development } \\
\text { Intel Technology Journal }\end{array}$ \\
\hline
\end{tabular}

Media coverage Online: Compound Semiconductor, Electronic Design News, EE Times, Semiconductor International, Semiconductor FabTech, Semiconductor Today, Silicon Strategies, Solid State Technology

Databases for the reproduction of printed documents: Lexis Nexis (English language)

Semiconductor specific outlets

IEEE Transactions on Semiconductor Manufacturing, Journal of Semiconductor Technology and Science, Journal of Semiconductors, Materials Science in Semiconductor Processing, Microelectronic Engineering

Conference proceedings

1995 - today: Proceedings of SPIE conferences

1997 - today: NGL Workshop papers and presentations

2001 - today: SEMATECH (later with SELETE and EUVA) hosted International EUVL Symposium papers and presentations

2001 - today: Workshops on EUVL masks, resists and source papers and presentations

2004 - today: SEMATECH, IMEC and SELETE hosted International Symposium on Immersion Lithography papers and presentations

2004 - today: SEMATECH hosted Lithography Forum (biannually) papers, presentations and surveys

lithography. Our data have been collected both retrospectively for the years in the run-up to the project and in 'real-time' since 2003. Apart from initial data collection from secondary sources, four main sources were utilized for triangulation purposes in order to heighten construct validity, as well as to prevent post-hoc rationalization and potential biases.

First, we analyzed a broad range of field documents (Table 2 for an overview). Among them were online materials (e.g., publicly available brochures, company periodicals, video footage of the organizations involved), archival data reproduced via databases (e.g., LexisNexis), and other documents issued by semiconductor industry actors (e.g., annual reports). Such sources provide secondary data but are deemed to be useful, as they allow a reconstruction of path processes on different levels of analysis over a longer period of time.

Secondly, to date, taking both the completed and the ongoing projects together, 119 semi-structured interviews have been conducted with semiconductor industry experts, company engineers, and senior executives. First, we identified interviewees by 'snowball sampling' and initial contact partners were asked to identify other potential respondents involved in coordinating industry activities. The interviews were conducted during on-site visits or by telephone, and recorded and transcribed verbatim for subsequent analyses. Except for seven, all the interviews were conducted by two members of 
the research team, allowing us to benefit from more adequate information gathering and recalling after the interview had taken place (Huber and Power 1985). The interview partners originated from the "organizational field" (DiMaggio and Powell 1983), whereby the focus level of analysis for the empirical study was the network of organizational actors involved in the process of path creation. With regard to the more micro level, we decided to pick up the level of the organization. Our decision for the level of the organizational field as the more macro level and the level of the organization as the more micro level is based on the fact that our interviewees mostly referred to these levels in our interviews and in their explanations of the technology development.

Thirdly, an annual panel was used each spring between 2007 and 2010. The panel interviews took place each time after a major industry conference to allow for first-hand and up-to-date industry insights. Five senior experts, who had different organizational and professional backgrounds and deep insights into the technology development process, were interviewed with the help of an interview guideline that has partly the same content as that of the semi-structured interviews, but is partly more general in nature, also venturing beyond the immediate industry needs by incorporating future technological options beyond 2020.

Fourthly, we draw extensively upon material from participant observation during on-site visits and, in particular, from major industry conferences; in the latter case both from participating at conferences (by members of the research project in 2001, 2005, 2009 and 2010) and by analyzing archival data like conference presentations, slides and public announcements. This is also in line with Giddens' (1984) assumptions about conducting field research, as attending such public conferences serves to strengthen the validity of our claims through formal and informal conversations and data gathering (e.g., roster listings, conference slides) in the course of such venues. We wrote down notes that took the form of direct and indirect quotations, subjects discussed and our own observations.

Finally, we conducted follow-up interviews and email correspondence with key respondents, as well as scholarly discussions with five U.S. and three European colleagues from the field of strategic management, research methods and organizational sociology as a form of member validation. Industry respondents were asked to comment on prior drafts of this study and their insights were integrated into two seminars in order to enhance internal validity. This process helped us to avoid misinterpreting the data, as triangulating by means of multiple sources and our prolonged engagement in the field since 2003 is in line with previous structuration theoretically informed research (e.g., Jarzabkowski 2008; Sydow and Windeler 1998) and, thereby, serves to enhance the trustworthiness of the data set.

\subsection{Data Analysis}

Although our data analysis did not occur in a linear fashion, it can be roughly divided into the following three stages: in the first stage we collected all the data in a case-study database to heighten reliability (Yin 2009), whereby our analysis is based upon the 'raw data' of 150 pages of field notes, 1,493 pages of interview transcripts, and roughly triple the amount of archival (incl. media coverage, both by online journals and trade periodicals via LexisNexis database, English language edition) as well as conference data (e.g., conference presentation slides). The data also included written comments and reports on the diverse organizations involved and the practices pursued in the field to coordinate the competing technological paths.

Stage two consisted of writing up condensed descriptions of how the different organizations and interorganizational networks interact to pursue joint technological options. The resulting detailed descriptions were discussed by the research team, thus sensitizing us to the way in which interorganizational coordination takes place in this industry and makes use of the respective field structures of signification, domination and legitimation.

In stage three, we condensed our empirical data (Table 3 for illustrative data concerning the constitutive features from different sources) and strengthened their interpretation from a structurationist perspective by not only referring to these aspects of structures (rules and resources) but also to the knowledgeability and reflexivity of agents and their potential to intervene into practices in the face of the dialectic of control. For this purpose we converted all the data for a combined analysis in atlas.ti, which is a software package for analyzing qualitative data. Based upon this, we attempted to comprehend the interorganizational efforts to pursue different technological paths by means of analyzing them, 


\title{
Table 3: Illustrative empirical data for the constitute features
}

\author{
Constitutive feature Illustrative interview data
}

Level interrelatedness "I think in the beginning these were really secret projects and there were really no discussion between very much competing companies, but I think right now, right now everything is already much more clear to the whole community, I think there are a lot of similarities in the way they approach things" (I-15)

Triggering event „Intel Capital itself was as important as any other VC [venture capitalist]. But on the other hand, with Intel Capital came Mama Intel if you like. And this was at the time and continues to be a strategic element to have EUV [Extreme Ultraviolet Lithography] as a part of the next device generation. So Intel Capital was no more no less a very capable entity like the other VCs. The bonus point was that there was Intel interested behind. The interaction in the supply chain continues to be mostly with Intel” (I-41)

Non-ergodic process "There were a whole list of suspect technologies so, you know, the more mature R\&D technologies were there, $x$-ray, soft x-ray which is now EUV, IPL [Ion-Beam Projection Lithography], EPL [Electron Projection Lithography], and then there were also second tier [...] So we knew that we had to be doing some sort of what we would be calling incubation programs with any new lithography technology, SEMATECH tries to set up a what we call; we never term it like this but it's like a incubation period where we start to have seeded development activities in that area. We try and identify what are the critical issues within that technology, try and build the right projects behind it" (I-31)

Self-reinforcing processes
"It's been even more important to have these international and inter-company groups such as this IEUVI [International EUV Initiative] to help set the vision for what needs to happen, and so the companies can see if we put all the pieces of the puzzle together in such and such a way, then we can see a commercial solution on a certain timescale, and that's what they need to be able to justify internal investment decisions and possibly customer engagement, and that's what's helped“(I-32)

Lock-in
"In the late 9os already - SEMATECH started to organize these annual workshops on NGL [Next Genera-
tion Lithography], so they brought together basically the whole Industry, so the IC manufacturers, also the
equipment suppliers, also some of the larger suppliers for that equipment, in which... and there were
technical presentations given on the progress and the way still to go until a solution would be there, and
then at the end of these workshops the industry, the IC manufacturers and also the suppliers had to make a
kind of a vote what they thought was the most likely technology as to our solution to take over at some
point in time, and at that moment that point in time was already way past at this moment. So I think out of
that in fact the majority of companies got convinced that EUV had the most potential. I think the other
initiatives also still lasted a little bit longer than that, but one after one there were kind of dropping out
because they saw that the industry... or there was not sufficient industry support" (I-27)
"The '9os have been really typically the decade in which people have begun really to trade off what they
wanted to do in a consortia with other companies, alliances, and so forth. And so these technologies started
with the [...] and then we ended up with five companies involved in this process from the semiconductor
side and that was the beginning" (I-33)

\section{Constitutive feature Illustrative media data}

\begin{tabular}{ll}
\hline Level interrelatedness & "ASML has joined SEMATECH's Lithography program at the College of Nanoscale Science and Engineer- \\
ing's (CNSE) Albany NanoTech Complex to further develop EUV lithography to ensure its future adoption. \\
ASML already partners with IMEC on EUV technology and infrastructure development. CNSE also has an \\
ASML built EUV 'Alpha' tool [...] Ron Kool, Vice President of EUV Lithography Systems at ASML. "Our \\
collaboration with SEMATECH and CNSE demonstrates the industry's commitment to EUV technology \\
and the infrastructure necessary to extend semiconductor shrink for another decade or more" (Osborne, \\
2010) \\
"A Next Generation Lithography (NGL) Workshop sponsored by International SEMATECH (Austin, Tex- \\
as) has recommended that the global semiconductor industry narrow the NGL options to two technolo- \\
gies, Extreme Ultraviolet (EUV), and Electron Projection Lithography (EPL), for commercialization. "One \\
of the goals of the NGL Workshop is to build global industry consensus on the NGL [Next Generation \\
Lithography] options. Today lithographers from around the world agree that EUV and EPL are the tech- \\
nologies necessary," said Gerhard Gross, Director of Lithography at International SEMATECH. "This \\
decision is particularly important as NGL technology moves out of the R\&D [Research and Development] \\
arena into the supplier area and the infrastructure needs to be prepared"' (Semiconductor Online, 2000)
\end{tabular}




\section{Table 3 continued: Illustrative empirical data for the constitute features}

\begin{tabular}{|c|c|}
\hline Constitutive feature & Illustrative media data \\
\hline Non-ergodic process & $\begin{array}{l}\text { "In the past year, the industry has experienced a major increase in the number of companies working on } \\
\text { EUV components [...] EUV continues to receive support as the best NGL solution. All equipment manu- } \\
\text { facturers have adjusted their roadmaps to now include EUV. This is a major shift from just one year ago, } \\
\text { when other options such as x-ray lithography (XRL), electron projection lithography (EPL) and ion projec- } \\
\text { tion lithography (IPL) were being pursued" (PR Newswire, 2001) }\end{array}$ \\
\hline $\begin{array}{l}\text { Self-reinforcing pro- } \\
\text { cesses }\end{array}$ & $\begin{array}{l}\text { "Infineon of Germany, ASM Lithography of the Netherlands and three American chip makers -- Intel, } \\
\text { Advanced Micro Devices and Motorola -- are underwriting the initiative, which involves an exotic new } \\
\text { technology known as extreme ultraviolet lithography, or E.U.V.. The research is considered crucial to } \\
\text { continuing advances in the semiconductor industry beyond 2004, when current technology is expected to } \\
\text { reach its limits in etching ever-smaller circuits on silicon" (Markoff, 2000) }\end{array}$ \\
\hline Lock-in & $\begin{array}{l}\text { "International Sematech here today said a new survey of photolithography experts shows growing support } \\
\text { for extreme ultraviolet (EUV) and electron projection lithography (EPL) as commercial technologies for } \\
\text { post-optical exposure tools in chip fabrication later this decade. The survey was conducted at Sematech's } \\
\text { Next Generation Lithography (NGL) Workshop held two weeks ago in Reston, Va., on Sept. 25. The re- } \\
\text { sults of the poll shows support for narrowing the options down to EUV and EPL for commercialization of } \\
\text { tools, said the Austin-based consortium" (EE Times, 2000) }\end{array}$ \\
\hline Multiple actors & $\begin{array}{l}\text { "SEMATECH [...] a global consortium of chipmakers, and KLA-Tencor Corporation [...] the world's lead- } \\
\text { ing supplier of process control and yield management solutions for the semiconductor and related indus- } \\
\text { tries, today announced KLA-Tencor has joined SEMATECH's Lithography Defect Reduction program at } \\
\text { the College of Nanoscale Science and Engineering [...] of the University at Albany" (Market Watch, 2011) }\end{array}$ \\
\hline
\end{tabular}

sensitized through our PCA perspective, which we will set out in more detail in the next section.

\section{$4 \quad$ PCA 'in Action'}

In this case study, we apply the PCA to the constitution or, more precisely, to the possible creation of a new technological path for the manufacturing tools of semiconductors. As shown as an overview in Table 4, the path under scrutiny displays six constitutive features that we elaborate upon subsequently.

\subsection{Level Interrelatedness}

The focus level of analysis concerns the creation of a new technological path, or more precisely, EUVL, from an existing one by mindful deviation and building momentum. For the creation of this specific technological path (as much as for the maintenance and possible extension of the established path), interorganizational research and development networks are extremely important (e.g., Browning and Shetler 2000; Carayannis and Alexander 2004; Okada 2008; Müller-Seitz and Sydow 2011; Sydow, Windeler, Schubert, and Möllering 2012). As for EUVL, SEMATECH appears critical as it is the leading global consortium for organizing the pre-competitive R\&D of the field of semiconductor manufacturing; among other means, by organizing and hosting field-wide venues:
"SEMATECH and its subsidiaries sponsor, host, and participate in a variety of public semiconductor industry meetings and events worldwide to enhance global cooperation and provide important forums for fostering dialogue and creating industry consensus [...] experts at SEMATECH's public conferences [s]hare data and methodologies [...] Rank critical issues required to bring $\mathrm{R} \& \mathrm{D}$ concepts to commercial production [...] Guide the industry in seeking effective solutions for future technology generations" (SEMATECH 2010).

This impression was confirmed when we participated in field-wide venues, as the leading conferences are organized or co-hosted by SEMATECH. Exemplary venues are the so-called Litho Forum focusing upon the lithography technologies that are competing to become the next-generation lithography, whereby EUVL is a leading candidate. Another key venue are the so-called International Technology Roadmap for Semiconductors (ITRS) workshops, named after an organization by the same name, which is a subsidiary of SEMATECH. This is the field-wide venue where actors develop a joint understanding of future technological milestones, offering guidance to the whole field. Therefore, the network level constitutes the focal level of analysis. As a level of analysis 'above' the network level of analysis, for various reasons we selected the organizational field in which the technological path is 


\section{Table 4: Empirical evidence for potential indicators of paths}

\begin{tabular}{|c|c|c|}
\hline Constitutive feature & Indicators & Illustrative evidence \\
\hline Level interrelatedness & $\begin{array}{l}\text { Actors and/or observers relate their activities (1) } \\
\text { recurrently, (2) intensively, and (3) to an important } \\
\text { extent not only to a focal, but at the same time to } \\
\text { more micro and macro levels of analysis }\end{array}$ & $\begin{array}{l}\text { R\&D consortia on the network level relate their } \\
\text { activities to the lower level of organization and the } \\
\text { upper level of the organizational field and vice versa }\end{array}$ \\
\hline Triggering event & $\begin{array}{l}\text { Actors and/or observers assess an incident as being } \\
\text { (1) decisive, (2) initiating self-reinforcing processes } \\
\text { for an option's likelihood to be prevalent in the } \\
\text { future... }\end{array}$ & $\begin{array}{l}\text { The most important triggering event was the proof- } \\
\text { of-concept of EUV by the consortium EUV LLC in } \\
\text { 2001; another triggering event was the delivery of } \\
\text { the first EUV alpha tool in } 2006\end{array}$ \\
\hline Non-ergodic process & $\begin{array}{l}\text { From the onset, (1) options of equal potential are } \\
\text { (2) narrowed down to (3) a final solution }\end{array}$ & $\begin{array}{l}\text { In the beginning, five next generation lithography } \\
\text { options existed; then, the support was focused on } \\
\text { EPL, which was initially the most likely candidate } \\
\text { apart from EUV; eventually, the support was solely } \\
\text { focused on EUV }\end{array}$ \\
\hline $\begin{array}{l}\text { Self-reinforcing pro- } \\
\text { cesses }\end{array}$ & $\begin{array}{l}\text { Over time, (1) (interorganizational) overarching } \\
\text { institutions that serve to formulate and pursue } \\
\text { joint objectives are established, (2), the design and } \\
\text { usage of complementary management systems } \\
\text { with regard to organizational aspects, and opera- } \\
\text { tions, (3) learning effects reinforce... }\end{array}$ & $\begin{array}{l}\text { Coordination effects are discernible, the worldwide } \\
\text { coordination of all actors involved in the EUV de- } \\
\text { velopment has improved significantly; in addition, } \\
\text { an interplay between commitment and performance } \\
\text { with regard to EUV is visible }\end{array}$ \\
\hline Lock-in & $\begin{array}{l}\text { Investments as well as sets of relations among } \\
\text { agents are stable or increase with regard to the } \\
\text { prevailing option, (2) investments in alternatives } \\
\text { are reduced, (3) alternative options are considered } \\
\text { to be niches ... }\end{array}$ & $\begin{array}{l}\text { Indicators suggest a 'soft' lock-in; investments in } \\
\text { EUV are stable and have even increased, support for } \\
\text { other options has almost disappeared and they are } \\
\text { regarded as niche technologies }\end{array}$ \\
\hline Multiple actors & $\begin{array}{l}\text { (1) number of actors (more than two), ( } 2 \text { ) proper- } \\
\text { ties of actors, (3) actors bound together by sets of } \\
\text { relations... }\end{array}$ & $\begin{array}{l}\text { R\&D consortia, e.g. SEMATECH, are of crucial } \\
\text { importance and strongly interrelated; intense and } \\
\text { ongoing communication between chip manufactur- } \\
\text { ers, tool manufacturers and suppliers }\end{array}$ \\
\hline
\end{tabular}

constituted. First, while the field concept seems similar to that of the industry, it is more open and yet emphasizes the importance not only of organizations, but also of technologies in use and institutionalized practices (Leblebici, Salancik, Copay, and King 1991) such as the so-called 'Moore's law', which serves as a guideline for technological development in the semiconductor industry (Moore 1965). It states that the number of transistors on an integrated circuit can be doubled every 18 to 24 months due to improvements in manufacturing semiconductors. Second, the concept of an organizational field is not restricted from a geographical point of view. This is helpful for our analysis, because this industry is highly internationalized and clarification of the regional agglomeration of activities is nevertheless one of the first research tasks (see, for respective evidence, Martin, Salomon, and Wu 2010). Third, an organizational field may even cut across the boundaries of a single industry and also includes additional actors such as regulatory agencies or capital providers, be they private or public. This suits our analysis of the EUVL path constitution process, because not only the semiconductor industry is crucial in this respect, but also its tool suppliers.

As a level 'below' the network, we selected the organization, because companies like Intel, Samsung or ASML do not outsource all their research and development activities:

"Important parts of the technological development take place at SEMATECH, that's tremendously important and, apart from that, every company has their own interests with regard to what they intend to pursue. Only to a limited extent, everybody [i.e., SEMATECH member] is able and willing to collaborate" (I-05).

This happens for various reasons: first, companies want to maintain their core competencies. Second, in consortia they do not have complete control over the financial resources provided, but - based upon their own resource endowments - have to negotiate 
with other members about their joint use. Third, when the technological development reaches a stage where the products are close to the market and companies want to have sole responsibility or bilateral development partnerships at the most.

With regard to the focal level of analysis and its upper and lower boundary levels, there is ample evidence that they are strongly interrelated. First of all, our interviewees frequently referred to the "industry" and to the "organization" level when they explained processes and events relating to the development of EUVL. In addition, many recurrent activities on the network level, for instance, are also oriented towards the organizational field and the organizational level as well (e.g., the activities of the ITRS as outlined above). A case in point regarding the former was the set-up of field-wide EUVL programs by R\&D consortia (I-46):

"SEMATECH tries to set up [...] and identify what are the critical issues within that technology [i.e. EUV], try to build the right projects behind it [...] and so you try and build [...] projects around that within the lithography technology division, which try to deliver value to our member companies" (I31).

Thereby, the message has been sent to national governments that this will be the technology of the future and, hence, should be supported in the form of government funding. Furthermore, presentations at industry conferences organized by semiconductor consortia are also related to investors, which have to be assured that this industry is able to introduce a new manufacturing technology that keeps production costs at a tolerable level in a timely manner and is thus worth investing in. Similarly, many network activities are related to the organizational level.

Recurrently, consortia award R\&D contracts to companies or universities in order to fill 'gaps' in the roadmap for EUVL, which means developing critical components that are crucial for the viability of this technology. Such measures that eliminate technological 'bottlenecks' also aim to convince other companies to start R\&D activities with regard to EUVL. On the other hand, there are activities on the levels of the organizational field or the organizational level that are related to the network level. The semiconductor company Intel, for example, invests via its corporate venture capital entity Intel Capital in vital EUVL suppliers and, thereby, enhances the incentives to back this technology on the levels of the network and the organizational field:
"I would say that we really start to look at [the technological development] from the start of the supply chain. As for EUVL, for instance [...] we really consider the whole supply chain from the beginning to the end and ponder where it is worth considering VC [venture capital] investments, speeding up the development and also to get other partners into our boat" (I-54).

Commenting on this, another interviewee mentioned that "the value of Intel was very huge, as [Intel Capital's engagement] lends legitimacy" (I65).

\subsection{Triggering Events}

With regard to the constitution of the EUVL path, several events are worth mentioning and constitute candidates for triggering events. An early incident was the decision by the industry consortium SEMATECH to organize the first conferences in 1998 and 200o. These venues got the discussion process about next-generation lithography started, and at subsequent conferences in 2000 and 2002, EUVL already emerged as the most likely candidate:

"At EUV there was a point in time [...] this was the SEMATECH workshop [...] when in 2002 EUV emerged as the next-generation lithography option [...]. The data [i.e. research results] that came out of this workshop and the data that the EUV LLC shared with the broader industry community have finally persuaded the people [i.e. other participants from the field] that EUV is the technology" (I-21).

The fact that EUVL was ranked highest by the global technological community provided this option with a significant amount of legitimacy in the field. The event with the most impact on the creation of a new technological path, nevertheless, was unquestionably EUV LLC's technological proof-of-concept of EUVL:

"They also initiated the [EUV] LLC [...] and then they said 'Well, take a look, it works!' Now there are several steps to say 'it works'. What they have shown is that, indeed, with this technology, with those mirrors they developed [...] it can be made. That was a lot, that was a critical step" (I-13). It triggered the setting-up of a large EUVL program at SEMATECH and of programs by national governments, as well as EUV-related R\&D programs by companies such as Zeiss, for example.

Other triggering events were the investments by Intel and also by its corporate venture-capital arm 
Intel Capital in crucial component suppliers for EUVL. These investments had two effects: first, they significantly improved the probability that the key technological challenges of EUVL could be solved eventually. Second, they showed the overwhelming interest of the market leader in this technology and, thereby, sent a powerful message to the field of the global semiconductor industry, which triggered further investments by other actors. In addition, EUVL was pushed forward by the more recent commitment of the South Korean chip manufacturer Samsung in 2005, which is now the second largest company in this industry. This commitment was indicated by the fact that Samsung became a core member of SEMATECH to benefit, among others, from SEMATECH's EUVL program. This step strengthened the belief in the ultimate success of EUV, which was important at this point in time, because this technology had run into several serious problems:

"Other companies became very aggressive and very interested in EUV lithography in the same timeframe. For example, SEMATECH actually picked up a member, Samsung, roughly during that period [to head the development for the consortium]" (I-37).

Since the proof-of-concept of EUVL in 2001, the focus has shifted to the question of whether this technology could eventually be used for mass manufacturing. In this respect, the delivery of the first EUVL alpha tools (i.e. prototypes) in 2006 was of vital importance, because it provided actors with the possibility to test and improve this technology more. Furthermore, semiconductor manufacturing tool producers such as formerly Phillips-owned ASML were able to generate a return on investment by the delivery of these alpha tools, which could then be reinvested into the development of beta tools. In sum, the occurrence of several events, big and small, some of them even occurring in a sequence, triggered the creation of EUVL and, hence, potentially of a new technological path.

\subsection{Non-ergodic Processes}

Non-ergodic processes could be observed in the global semiconductor industry in the late $1990 \mathrm{~s}$ when actors aimed at enhancing the established optical lithography and at extending its reach, but were already giving top priority to the quest for a radically different alternative. The view prevailed that optical lithography could not print patterns below $45 \mathrm{~nm}$ half pitch. In order to print smaller patterns, industry respondents considered a novel kind of lithography imperative. For this reason, in 2004 experts were still working on five different options of so-called next-generation lithography: these five options included - apart from EUVL as already at that time the most likely successor of present optical lithography - Electron Projection Lithography (EPL), Ion Projection Lithography (IPL), Proximity X-Ray Lithography (PXL), and Projection Electron Lithography (PEL).

Initially, and as characteristic of a non-ergodic process, it was far from clear which candidate would succeed. In fact, at the beginning of this process, EUVL was not even regarded as the most likely candidate. The industry consortium SEMATECH organizes a global conference on this matter each year. At the first conference in 1998, EPL and its related consortium PREVAIL was the winner, measured by a ranking of lithography scientists at the end of the conference. As a consequence, Intel established the so-called EUV LLC in order to support this technology. This consortium included several chip manufacturers and also three national laboratories from the U.S. At the second conference, EUVL became the first ranked option, even though EPL was only narrowly beaten:

"As from 1995 there were biannual workshops organized in which these champion groups were promoting data and results on their technology of choice and I think in the late 1990 s in fact, EUV came out of that technology as the clear winner as the technology that has the largest potential to take over from optical lithography in the future. But still, there were companies like the ones focused on EPL that continued to work on their preferred option and like, for example, Nikon together with IBM have been running a joint program on EPL for a number of years" (I-15).

The EUV LLC gained further momentum when the semiconductor firms Infineon and Micron joined the consortium in 2000 and IBM followed in 2001. The latter was particularly important, because until then IBM had exclusively promoted EPL. EUV LLC's technological proof of principle in 2001 then eventually turned the balance in favor of EUVL. As a response to EUV LLC's technological proof of principle, the successful members of the EUV LLC consortium, together with other members of the industry, then strategically retransferred the further process of EUVL re- 
search and development to SEMATECH as the accepted, neutral locale for collaborative technology development. The EPL consortium PREVAIL was dissolved shortly after the success of its rival consortium. To date, EUVL is the only remaining candidate with promising potential to be the nextgeneration lithography, even though it is still unclear if this technology will eventually be introduced into mass manufacturing because many problems remain to be solved. Surprisingly, though, to date the only competing option to EUVL is not a new alternative, but immersion lithography, which represents only an extension of the current technological path of optical lithography.

\subsection{Self-reinforcing Processes}

Coordination effects pertaining to the development of EUVL are already discernible. The coordination between different consortia in the field, particularly regarding consortia originating from different regions, as well as the integration of new actors into the R\&D network, has been much improved. There are several semiconductor consortia that are focused at least to a certain extent on EUVL. These consortia, in addition, have overlapping as well as complementary tasks and originate from different world regions: the U.S., Europe, Japan, South Korea, and Taiwan. In order to cover all critical aspects of EUVL, on the one hand, and to avoid too much worldwide duplication of R\&D efforts, on the other, actors created a 'vehicle' called International EUV Initiative or IEUVI for short. This loose (meta-) network of consortia serves as a global forum of exchange with regard to EUVL and, as it provides the structures needed for more effective coordination, is of tremendous importance for tackling the worldwide challenges of EUVL with limited resources by setting technological standards that help to coordinate the various activities. Over time, the field-wide coordination has significantly improved, even though it is by no means a process without friction. In addition, EUV as a technological option has benefited from the industry's tendency to stick to known technological solutions:

"It's true that our industry is very conservative, so basically companies don't want to change anything if they can still continue for another six months with what they are doing today. And in that sense I think that was definitely a plus for EUV that it was something that people could un- derstand easier and was more kind of an extension of what they were doing today rather than an abrupt evolution or revolution" (I-15).

Not only coordination, but also some complementarity effects are already observable with regard to the activities of SEMATECH, not only with respect to structures of signification and legitimation but also domination. This is because this very influential research and development consortium consists of 13 organizations that not only represent half of the worldwide semiconductor market (SEMATECH 2010) but have worked together recurrently over many years. In addition, it provides joint resources, for instance in the form of joint testing facilities, which all SEMATECH members can draw upon. Such financial and strategic commitments are worth noting, as they serve as indicators for complementarity effects.

Thus, as in most cases of path dependence, not only one but several self-reinforcing mechanisms seem to be at work in the field of semiconductor manufacturing technology. What is more, these mechanisms cannot only be identified for the established optical, but also for post-optical lithography, even though the reinforcement forces are still too weak to speak of a new technological path (EUVL) having been created.

\subsection{Lock-in}

To start with, we have to concede that despite an ongoing development process which started more than ten years ago there is still no real lock-in for EUVL, as nobody knows for sure whether this technology will ever be introduced into mass manufacturing. Moreover, another competing option might exist that has not yet been perceived or anticipated as relevant, but might surface, e.g., one stemming from a related arena such as enhanced optical lithography. However, several indicators suggest that a 'soft' lock-in for EUVL has already occurred, as the pursuit of alternative technological paths already appears to be quite unlikely; at least if the technological challenges can be overcome. More specifically, the indicators suggest that investments have increased significantly with regards to EUVL:

"You can find many people that simply say 'We have no choice anymore' and if EUV is not going to succeed this would have hefty consequences" (I-74).

This holds true regardless of whether we focus on consortia, companies or regions. As mentioned 
above, SEMATECH set up a large EUVL program in 2002 after EUV's proof-of-concept. The latest EUVL program, which was set up in 2008, even exceeded the earlier one, as the State of New York massively subsidized it in order to create new jobs for the region. This manifests, among other things, in conference series that are explicitly geared towards EUVL and which we attended for data collection purposes. In contrast, by and large no other conference series of comparable size and with nearly as important key attendees exists to date, which serves as a further indicator of the increasing dominance of EUVL as next-generation lithography.

Additionally, key companies in this organizational field - such as the world's largest producer of semiconductor manufacturing tools ASML - recently started an EUVL-related R\&D program with a volume of about one billion \$ U.S. From the perspective of ASML, this action is clearly backing for EUVL. Furthermore, huge EUVL initiatives have also been started in Japan in recent years, although this region had been skeptical with regard to the technology for a long time.

By contrast, investments in alternative options have been sharply reduced. Whereas at the beginning of the process five options received at least some support, the investments were soon focused on two options, EUVL and EPL. From a technological point of view, EPL might have been worth pursuing as well. However, due to the dominantly shared assumption that EUVL ought to be pursued because of an increasing engagement of powerful actors by means of coordinating joint efforts, over time the EPL consortium PREVAIL was dissolved and the Japanese EPL program phased out and was replaced by an EUVL program. To date, all five world regions and their respective actors support EUVL as a next-generation lithography option. In this connection, one interviewee aired the following:

"The process forced people to narrow down, so EUV came out as the winner and then the other companies, who initially voted on something else - step by step - started to change position and admitted... or basically said: Well, we have to work with the majority, there is no money to keep developing everything, all the alternatives" (I-27). Third, as yet the only remaining alternatively viable option that is being promoted by SEMATECH at this point in time, nano-imprint lithography, is considered a niche technology due to its low throughput, i.e. the amount of chips produced in a certain period of time. To sum up, even though the ultimate success of EUVL is still questionable, various indicators suggest a 'soft' lock-in at this point in time.

\subsection{Multiple Actors}

A multitude of collective, strongly interlinked actors are important for the constitution of the EUVL path. For instance, several $R \& D$ consortia are worth mentioning. The most relevant consortium with regard to EUVL is of course SEMATECH. It consists of the largest semiconductor firms from all over the world, which are formally equal partners (Browning and Shetler 2000; Müller-Seitz and Sydow 2011; Sydow, Windeler, Schubert, and Möllering 2012). The prominent role it plays is legitimated by its assumed neutrality; that is, the promotion of several technologies. Today the consortium not only organizes the construction of the industry's innovation activities, but also R\&D for precarious aspects of the technological infrastructure, not only for developing a solution, but also for extending the current optical path. Over the years, the network structure of the consortium shifted not only from the U.S. to a more global, but also from mainly horizontal to vertical cooperation, i.e. it has started to coordinate joint research projects with suppliers for the much-needed equipment for manufacturing semi-conductors (Carayannis and Alexander 2004). Nevertheless, only semiconductor companies are able to become core members of this consortium, although related initiatives are offered, in which participants from the entire organizational field are invited to participate.

Besides SEMATECH, ASET and SELETE in Japan, IMEC, MEDEA and LETI in Europe are consortia or consortia-like network forms of organization that are crucial to the constitution of the EUVL path; the IEUVI is the platform where all these consortia communicate and coordinate their activities with each other. The EUV LLC stopped its R\&D activities after the proof-ofprinciple. A relatively recent consortium solely related to EUVL is INVENT at the University of Albany - SUNY, which includes chip manufacturers and also suppliers.

On the organizational level, chip manufacturers and producers of semiconductor manufacturing tools, as well as their suppliers, are relevant. The chip manufacturers most interested in EUVL are Intel, AMD and IBM from the U.S., and Samsung 
from South Korea, which are all SEMATECH members. Furthermore, there are only three tool manufacturers or system integrators that are relevant: the market leader ASML from the Netherlands, as well as Nikon and Canon from Japan. In addition, a multitude of suppliers for EUVL exist, but despite the large overall number, only one to three suppliers exist worldwide for many critical components. Chip manufacturers, tool manufacturers and suppliers are linked in or even locked into supply chains and are engaged in an intense and ongoing communication process. Because the failure to develop a critical component could threaten the constitution of the entire EUVL path, these actors are strongly interrelated. Besides, several public organizations and investors are of importance with regard to EUVL. National and supranational governments in countries such as Japan or Germany, as well as the European Union, have not only started but cannot easily stop EUVL programs. In the U.S., the Department of Defense and several states, first and foremost the states of Texas and increasingly of New York, also promote the development of EUVL. Finally, venture capitalists are relevant for some of the EUVL suppliers. They sometimes invest in cooperation with corporate venture capital entities of semiconductor firms, most notably Intel Capital. However, due to the timeconsuming development process of EUV, venture capitalists are rather reluctant to invest in this technology.

Overall, the 'PCA in action' represents a first attempt to illustrate the challenges inherent in conducting research that is informed by path concepts, the concept of path constitution as informed by structuration theory in particular and how they can be managed in empirical investigations. Starting with the definition, a careful operationalization of the key elements then served as a guide for the subsequent presentation and discussion of our findings from the semiconductor industry.

\section{Conclusions and Directions}

The starting point of this paper was the observation that the rising interest in path concepts, including path dependence and path creation, predominantly appertains to theoretical debates, but not to their methodological implications. We intended to com- plement this discourse by designing and presenting the PCA as a comprehensive, theoretically informed methodology for predominantly qualitative analyses in a post-positivistic manner, offering a fruitful step for further analyses of these processes (in a similar vein Ketchen, Boyd, and Bergh 2008). Research on path dependence and path creation, at least so far, is a field which has been characterized by a rather broad range of methods, making the integration of empirical insights difficult. Not least for this reason, it is a very suitable field in which to advance a more comprehensive and yet detailed research methodology which helps to analyze the constitution of technological, institutional and organizational paths.

The major contribution of this paper can be seen in its offering a first step towards such a comprehensive and yet detailed approach that is informed by the concepts of both path dependence and path creation and - in sharp contrast to at least the earlier intentions of the proponents of the latter (Garud and Karnøe 2001) - integrates them into a more encompassing understanding of path constitution. Towards this end, it makes use of structuration theory (Giddens 1984). In consequence, we contribute to the literature by paying attention to the definition of technological, institutional and organizational paths, which we have characterized by means of six constitutive features, that is, level interrelatedness, triggering events, non-ergodic processes and self-reinforcing processes, lock-ins and multiple actors. We have also provided several indicators for analyzing these features in order to allow for a diffusion of these ideas on a common basis.

Moreover, we have elucidated the PCA 'in action' by applying it to a longitudinal and multilevel analysis in the field of semiconductor manufacturing. While applying the PCA and reflecting upon how this methodology can be and actually is put into practice, we enriched our theoretically informed definition and presented indicators by means of concrete examples from our field research. By doing so, we hope to have offered a pragmatic, yet theoretically informed guideline for other researchers interested in the analysis of paths, not necessarily just technological ones.

In order to elaborate upon our methodological contribution further, it appears fruitful to differentiate our PCA from related methodological approaches. Perhaps a case-study approach resembles the PCA most, no matter whether it makes use of qualitative or quantitative data or even follows a mixed-method 
approach. However, in - at least - slight contrast to many case studies - as set out most prominently by Yin $(1981,2009)$ for the social sciences - we do not rely solely on temporary phenomena (see the discussion by Gibbert, Ruigrok, and Wicki 2008) or exclude experimental approaches (e.g., Koch, Eisend, and Petermann 2009), but demand longitudi$\mathrm{nal} /$ processual investigations and multilevel level analyses of multi-actor constellations (see also Koch's 2011 approach to combine discursive and case-study approaches). That is, the PCA focuses on more than temporary phenomena in a historically sensitive manner and is inevitably demanding (due to being theoretically informed) both, longitudinal as well as multiple level data. However, it may often be important to use temporal bracketing for pragmatic purposes (Langley 1999). Moreover, the PCA should under no circumstances be confused with grounded theory (Glaser and Strauss 1967), as this methodology is by definition - and in sharp contrast to the PCA - not ex ante theoretically informed. As opposed to experimental designs, the PCA is not detached from the respective context or research object, demanding a lower level of abstraction. Content analysis, like event analysis, is another method that might be applicable (Gephart 2004; Krippendorf 2004), but this approach also only captures a potential part of the PCA. This is also true for conventional surveys which, however, usually fail to unpack historical causalities. Finally, ethnographic work can be a method employed in the course of a PCA, but in most cases it is not theoretically a priori as informed as the PCA (Goulding 2005; Rosen 1991: 12). In sum, the PCA's key idea might be summarized as being a theoretically a priori informed methodology open to a broad range of not only empirical settings but also methods (echoing Garud, Kumaraswamy, and Karnøe 2010; Dobusch and Kapeller 2013).

Despite the advancements presented, a number of limitations have to be taken into consideration: First, when applying the PCA, the investigation at multiple levels of analysis might incorporate conflicting perspectives, not least due to the postpositivistic nature of our research design (Lincoln and Guba 1985). For instance, in the course of our analyses we interviewed members from different corporations and with different backgrounds. When asked about the same phenomena, sometimes differing opinions were aired, e.g., with regard to the importance and/or impact of a path. Hence, the triangulation of perspectives - actually perceived as being an advantage of qualitative inquiries in the social sciences (Seale 1999, with regard to 'accounting for contradictions') - can lead to disagreements, and it remains an open question as to how to deal with them. Second, in our application of the methodology, at least as presented in this paper, we referred solely to qualitative data. The lack of quantitative data included in our PCA may be considered a shortcoming insofar as we are not able to relate to other, quantitatively oriented discourses properly; this, however, should be possible if respective data are at hand (e.g., Jansen 2004). Thirdly, we relied upon an understanding of path constitution informed by Giddens' overarching idea of social constitution processes (Windeler 2003). Relating to the previous argument, and in line with criticism on structuration theory per se (e.g., Archer 1995), it might be beneficial to augment the theoretical approach by integrating aspects of perspectives other than the ones we have drawn on (i.e. the theories of path dependence and path creation), which also allow for a more precise operationalization of different indicators.

Future research endeavors comprising the empirical analysis and comparison of different types of paths might deliver intriguing results. For example, what do technological, organizational and/or institutional paths have in common, and where are the (potential) differences from a theoretical stance, as well as with regard to empirical analyses? How do they perhaps interact in producing an outcome that has been considered merely a technological lock-in so far? In addition, it is worth considering broadening the empirical scope of analysis to further settings. For instance, apart from analyzing other industries in general, consumer industries in particular might deliver results that differ from our path-oriented findings with regard to firms producing industrial goods like semiconductor manufacturing tools. This assumption can be traced back to the observation that in such industries the actor constellations differ substantially, in particular with regard to the end-user putting more emphasis on network effects as an important mechanism of selfreinforcement. Furthermore, flanking the research process by incorporating quantitative analyses might foster the validity and significance of the conclusions drawn. This is deemed appropriate, as the PCA was not designed as a pure 
antipode, but as a comprehensive methodology embracing, wherever appropriate, quantitative approaches in the social sciences (Creswell and Clark 2007).

\section{Acknowledgements}

We thank the Volkswagen Foundation, Germany, for funding this research under grant AZ II/80308, the German Research Foundation (DFG) for additional funding from grant MU 3070/1-1, as well as our interviewees for their time and patience. An earlier version of this paper was presented at the 2009 Annual Meeting of the European Academy of Management (EURAM) in Liverpool. Finally, we are indebted to the helpful guidance of Business Research Department Editor Peter Walgenbach as well as two anonymous reviewers for their constructive criticism.

\section{References}

Abbott, Andrew (1992): What Do Cases Do?, in: Charles C. Ragin and Howard S. Becker (eds.): What is a Case?, Cambridge University Press: Cambridge, 53-82.

Abbott, Andrew (1997): On the Concept of Turning Point, Comparative Social Research, 16: 85-106.

Aguinis, Herman, Charles A. Pierce, Frank A. Bosco, and Ivan S. Muslin (2009): First Decade of Organizational Research Methods: Trends in Design, Measurement, and Data-Analysis Topics, Organizational Research Methods, 12 (1): 69-112.

Ansari, Shahzad and Raghu Garud (2009): Inter-Generational Transitions in Socio-Technical Systems: The Case of Mobile Communications, Research Policy, 38 (2): 382-392.

Antonelli, Cristiano (1997): The Economics of Path-Dependence in Industrial Organization, International Journal of Industrial Organization, 15 (6): 643-675.

Archer, Margaret S. (1995): Realist Social Theory: The Morphogenetic Approach, Cambridge University Press: Cambridge.

Arthur, W. Brian (1989): Competing Technologies, Increasing Returns, and Lock-In by Historical Events, The Economic Journal, 99 (394): 116-131.

Arthur, W. Brian (1994): Increasing Returns and Path Dependency in the Economy, University of Michigan Press: Ann Arbor, MI.

Barnes, William, Myles Gartland, and Martin Stack (2004): Old Habits Die Hard: Path Dependency and Behavioral Lock-In, Journal of Economic Issues, 38 (2): 371-377.

Baum, Joel A. C. and Brian S. Silverman (2001): Complexity, Attractors, and Path Dependence and Creation in Technological Evolution, in: Raghu Garud and Peter Karnøe (eds.): Path Dependence and Creation, Erlbaum: Mahwah, NJ et al., 169-209.

Bennett, Andrew and Colin Elman (2006): Complex Causal Relations and Case Study Methods: The Example of Path Dependence, Political Analysis, 14 (3): 250-267.

Beyer, Jürgen (2010): The Same or Not the Same: On the Variety of Mechanisms of Path Dependence, International Journal of Human and Social Sciences, 5 (1): 1-11.

Bitektine, Alex (2008): Prospective Case Study Design: Qualitative Method for Deductive Theory Testing, Organizational Research Methods, 11 (1): 160-180.

Browning, Larry D. and Judy C. Shetler (2000): Sematech: Saving the U.S. Semiconductor Industry, Texas A\&M University Press: College Station, TX.

Carayannis, Elias G. and Jeffrey M. Alexander (2004): Strategy, Structure and Performance Issues of Precompetitive R\&D Consortia: Insights and Lessons Learned From SEMATECH, IEEE Transactions on Engineering Management, 51 (2): 226-232.

Cohen, Ira J. (1989): Structuration Theory: Anthony Giddens and the Constitution of Social Life, St. Martin's Press: New York, NY.

Collier, Ruth B. and David Collier (1991): Shaping the Political Arena: Critical Junctures, the Labor Movement, and Regime Dynamics in Latin America, Princeton University Press: Princeton, NJ.

Creswell, John W. and Vicki L. Plano Clark (2007): Designing and Conducting: Mixed Methods Research, Sage: Thousand Oaks, CA et al.

Cusumano, Michael A., Yiorgos Mylonadis, and Richard S. Rosenbloom (1992): Strategic Maneuvering and Mass-Market Dynamics: The Triumph of VHS Over Beta, Business History Review, 66 (Special Issue 1): 51-94.

David, Paul A. (1985): Clio and the Economics of QWERTY, American Economic Review, 75 (2): 332-337.

David, Paul A. (2001): Path dependence, its critics and the quest for "historical economics", in: Pierre Garrouste and Stavros Ioannides (eds.): Evolution and Path Dependence in Economic Idea: Past and Present, Elgar: Cheltenham, UK, 15-41.

David, Paul A. (2007): Path Dependence: A Foundational Concept for Historical Social Science, Cliometrica, 1 (2): 91-114.

DiMaggio, Paul J. and Walter W. Powell (1983): The Iron Cage Revisited: Institutional Isomorphism and Collective Rationality in Organizational Fields, American Sociological Review, 48 (2): 147160.

Dobusch, Leonhard and Jakob Kapeller (2013): Striking New Paths: Theory and Method in Path Dependence Research, Schmalenbach Business Review, 65 (in print).

Dosi, Giovanni (1982): Technological Paradigms and Technological Trajectories, Research Policy, 11 (3): 147-162.

Dosi, Giovanni and Luigi Orsenigo (1988): Coordination and Transformation: An Overview of Structures, Behaviours and Change in Evolutionary Environments, in: Giovanni Dosi, Christopher Freeman, Richard Nelson, Gerald Silverberg, and Luc Soete (eds.): Technical Change and Economic Theory, Pinter: New York, NY, 13-37.

Edmondson, Amy C. and Stacy E. McManus (2007): Methodological Fit in Management Field Research, Academy of Management Review, 32 (4): 1155-1179.

Garud, Raghu and Peter Karnøe (2001): Path Creation as a Process of Mindful Deviation, in: Raghu Garud and Peter Karnøe (eds.): Path Dependence and Creation, Erlbaum: Mahwah, NJ et al., 1-38.

Garud, Raghu and Peter Karnøe (2003): Bricolage Versus Break- 
through: Distributed and Embedded Agency in Technology Entrepreneurship, Research Policy, 32 (2): 277-300.

Garud, Raghu, Arun Kumaraswamy, and Peter Karnøe (2010): Path Dependence or Path Creation?, Journal of Management Studies, 47 (4): 760-774.

Gephart, Robert P. (2004): Qualitative Research and the Academy of Management Journal, Academy of Management Journal, 47 (4): 454-462.

Gibbert, Michael, Winfried Ruigrok, and Barbara Wicki (2008): What Passes as a Rigorous Case Study?, Strategic Management Journal, 29 (13): 1465-1474.

Giddens, Anthony (1984): The Constitution of Society: Outline of the Theory of Structuration, Polity Press: Cambridge.

Giddens, Anthony (1989): A Reply to My Critics, in: David Held and John B. Thompson (eds): Social Theory of Modern Societies: Anthony Giddens and his Critics, Cambridge University Press: Cambridge, 249-301.

Glaser, Barney G. and Anselm L. Strauss (1967): The Discovery of Grounded Theory: Strategies for Qualitative Research, Aldine: Chicago, IL.

Goulding, Christina (2005): Grounded Theory, Ethnography and Phenomenology, European Journal of Marketing, 39 (3/4): 294308.

Granovetter, Mark (1985): Economic Action and Social Structure: The Problem of Embeddedness, American Journal of Sociology 91 (3): 481-510.

Gwyn, Chuck and Stefan Wurm (2009): EUV LLC: A Historical Perspective, in: Vivek Bakshi (ed.): EUV Lithography, SPIE Press: Bellingham, WA, 55-101.

Hess, Sebastian, Daniela Kleinschmitt, Ludwig Theuvsen, Stephan von Cramon-Taubadel, and Ulrike Zschache (2010): Explaining Path Dependence Through Discourse Analysis: The Case of the Seasonal Farm Workers in Germany, in: Georg Schreyögg and Jörg Sydow (eds.): The Hidden Dynamics of Path Dependence, Palgrave-Macmillan: Basingstoke et al., 197-216.

Huber, George P. and Daniel J. Power (1985): Retrospective Reports of Strategic-Level Managers: Guidelines for Increasing Their Accuracy, Strategic Management Journal, 6 (2): 171-180.

Jansen, Karen J. (2004): From Persistence to Pursuit: A Longitudinal Examination of Momentum During the Early Stages of Strategic Change, Organization Science, 15 (3): 276-294.

Jarzabkowski, Paula (2008): Shaping Strategy as a Structuration Process, Academy of Management Journal, 51 (4): 621-656.

Jepperson, Ronald and John W. Meyer (2011): Multiple Levels of Analysis and the Limitations of Methodological Individualisms, Sociological Theory, 29 (1): 54-73.

Jick, Todd D. (1979): Mixing Qualitative and Quantitative Methods: Triangulation in Action, Administrative Science Quarterly, 24 (4): 602-611.

Ketchen, David J., Brian K. Boyd, and Donald D. Bergh (2008): Research Methodology in Strategic Management: Past Accomplishments and Future Challenges, Organizational Research Methods, 11 (4): 643-658.

Koch, Jochen (2011): Inscribed Strategies: Exploring the Organizational Nature of Strategic Lock-In, Organization Studies, 32 (3): 337-363.
Koch, Jochen, Martin Eisend, and Arne Petermann (2009): Path Dependence in Decision-Making Processes: Exploring the Impact of Complexity Under Increasing Returns, Business Research, 2 (1): 67-84.

Krippendorff, Klaus (2004): Content Analysis: An Introduction to Its Methodology, Sage: Thousand Oaks, CA et al.

Langley, Ann (1999): Strategies for Theorizing From Process Data, Academy of Management Review, 24 (4): 691-710.

Langlois, Richard N. and W. Edward Steinmueller (1999): The Evolution of Competitive Advantage in the Worldwide Semiconductor Industry, 1947-1966, in: David C. Mowery and Richard R. Nelson (eds.): Sources of Industrial Leadership: Studies of Seven Industries, Cambridge University Press: Cambridge, 19-78.

Leblebici, Huseyin, Gerald R. Salancik, Anne Copay, and Tom King (1991): Institutional Change and the Transformation of Interorganizational Fields: An Organizational History of the U.S. Radio Broadcasting Industry, Administrative Science Quarterly, 36 (3): $333-363$.

Lincoln, Yvonna S. and Egon G. Guba (1985): Naturalistic Inquiry, Sage: Beverly Hills, CA et al.

Linden, Greg, David C. Mowery, and Rosemarie H. Ziedonis (2000): National Technology Policy in Global Markets: Developing Next-Generation Lithography in the Semiconductor Industry, Business and Politics, 2 (2): 93-113.

Mahoney, James (2001): The Legacies of Liberalism: Path Dependence and Political Regimes in Central America, Johns Hopkins University Press: Baltimore, MD.

Market Watch (2011): KLA-Tencor and SEMATECH Partner to Advance EUV Lithography Technology at UAlbany NanoCollege, http://www.marketwatch.com/story/kla-tencortm-and-sematech -partner-to-advance-euv-lithography-technology-at-ualbanynanocollege-2011-06-21 (Access date: 2011-08-24).

Markoff, John (2000): Global Effort to Make Machines that Make Chips, New York Times, 2000-12-12.

Martin, Xavier, Robert M. Salomon, and Zheying Wu (2010): The Institutional Determinants of Agglomeration: A Study in the Global Semiconductor Industry, Industrial and Corporate Change, 19 (6): 1769-1800.

Mayntz, Renate (2004): Mechanisms in the Analysis of Social Macro-Phenomena, Philosophy of the Social Sciences, 34 (2): 237-259.

McGrath, Dylan and Mark LaPedus (2011): Analysis: Litho World Needs a Shrink, http://www.eetimes.com/electronics-news/ 4213996/Analysis--Litho-world-needs-a-shrink (Access date: 2011-03-16).

Meyer, Uli and Cornelius Schubert (2007): Integrating Path Dependency and Path Creation in a General Understanding of Path Constitution: The Role of Agency and Institutions in the Stabilisation of Technological Innovations, Science, Technology \& Innovation Studies, 3 (1): 23-44.

Moore, Gordon E. (1965): Cramming More Components Onto Integrated Circuits, Electronics, 38 (8): 114-117.

Müller-Seitz, Gordon and Jörg Sydow (2011): Terminating Institutionalized Termination: Why SEMATECH Became More Than a Temporary System, in: Gino Cattani, Simone Ferriani, Lars Frederiksen, and Florian Täube (eds.): Advances in Strategic Management: Project-Based Organizing and Strategic Management, Emerald: Bingley, 147-186. 
North, Douglas C. (1990): Institutions, Institutional Change, and Economic Performance, Cambridge University Press: Cambridge.

Okada, Yoshitaka (2008): From Vertical to Horizontal Inter-Firm Cooperation: Dynamic Innovation in Japan's Semiconductor Industry, Asia Pacific Business Review, 14 (3): 379-400.

Page, Scott (2006): Path Dependence, Quarterly Journal of Political Science, 1 (1): 87-115.

Petermann, Arne (2010): Pfadabhängigkeit und Hierarchie: Zur Durchsetzungskraft von selbstverstärkenden Effekten in hierarchischen Organisationen, http://www.diss.fu-berlin.de/diss/ receive/FUDISS_thesis_000000019882 (Access date: 2012-0414)

Piekkari, Rebecca, Catherine Welch, and Eriikka Paavilainen (2009): The Case Study as Disciplinary Convention: Evidence From International Business Journals, Organizational Research Methods, 12 (3): 567-589.

Pierson, Paul (2000): Increasing Returns, Path Dependence, and the Study of Politics, American Political Science Review, 94 (2): 251-267.

Pierson, Paul (2004): Politics in Time: History, Institutions, and Social Analysis, Princeton University Press: Princeton, NJ.

Pratt, Michael G. (2008): Fitting Oval Pegs Into Round Holes. Tensions in Evaluating and Publishing Qualitative Research in Top-Tier North American Journals, Organizational Research Methods, 11 (3): 481-509.

Ragin, Charles C. (2006): Case-Oriented Comparative Methods, in: David de Vaus (ed.): Research Design: Vol. IV, Sage: London, 21-41.

Rosen, Michael (1991): Coming to Terms With the Field: Understanding and Doing Organizational Ethnography, Journal of Management Studies, 28 (1): 1-24.

Schubert, Cornelius and Arnold Windeler (2007): Pfadkreationsnetzwerke aus methodischer Sicht, in: Hagen Hof and Ulrich Wengenroth (eds.): Innovationsforschung: Ansätze, Methoden, Grenzen und Perspektiven, Lit-Verlag: Hamburg et al., 117-126.

Seale, Clive (1999): The Quality of Qualitative Research, Sage: London.

SEMATECH (2010): Conferences and Events, http://www. sematech.org/meetings/events.htm (Access date: 2010-01-16).

Street, Christopher T. and R. Brent Gallupe (2009): A Proposal for Operationalizing the Pace and Scope of Organizational Change in Management Studies, Organizational Research Methods, 12 (4): 720-737.

Suddaby, Roy (2006): From the Editors: What Grounded Theory is Not, Academy of Management Journal, 49 (4): 633-642.

Sydow, Jörg and Arnold Windeler (1998): Organizing and Evaluating Interfirm Networks: A Structurationist Perspective on Network Processes and Effectiveness, Organization Science, 9 (3): $265-284$

Sydow, Jörg, Frank Lerch, and Udo Staber (2010): Planning for Path Dependence? The Case of a Network in the BerlinBrandenburg Optics Cluster, Economic Geography, 86 (2): 173195.

Sydow, Jörg, Georg Schreyögg, and Jochen Koch (2009): Organizational Path Dependence: Opening the Black Box, Academy of Management Review, 34 (4): 689-709.
Sydow, Jörg, Arnold Windeler, Cornelius Schubert and Guido Möllering (2012): Organizing R\&D Consortia for Path Creation and Extension: The Case of Semiconductor Manufacturing Technologies, Organization Studies, 33 (7): 907-936.

Tashakkori, Abbas and Charles Teddlie (eds.) (2003): Handbook of Mixed Methods in Social and Behavioral Research, Sage: Thousand Oaks, CA et al.

Valorinta, Mikko, Henri Schildt, and Juha-Antti Lamberg (2011): Path Dependence of Power Relations, Path-breaking Change and Technological Adaptation, Industry and Innovation, 18 (8): 765790 .

Vergne, Jean-Philippe and Rodolphe Durand (2010): The Missing Link Between the Theory and Empirics of Path Dependence: Conceptual Clarification, Testability Issue, and Methodological Implications, Journal of Management Studies, 47 (4): 736-759.

Windeler, Arnold (2003): Kreation technologischer Pfade: ein strukturationstheoretischer Analyseansatz, in: Georg Schreyögg and Jörg Sydow (eds.): Strategische Prozesse und Pfade, Gabler: Wiesbaden, 295-328.

Windeler, Arnold and Jörg Sydow (2001): Project Networks and Changing Industry Practices: Collaborative Content Production in the German Television Industry, Organization Studies, 22 (6): 1035-1060.

Yin, Robert K. (1981): The Case Study Crisis: Some Answers. Administrative Science Quarterly, 26 (1): 58-65.

Yin, Robert K. (2009): Case Study Research, 4th ed., Sage: Thousand Oaks, CA et al.

\section{Biographies}

Dr. Jörg Sydow is a Professor of Management at the School of Business \& Economics of the Freie Universität Berlin and a Visiting Professor at the University of Strathclyde's Graduate School of Business. He is on the editorial board of leading scholarly journals including Organization Studies, Organization Science and the Academy of Management Review. His research focuses upon organization and information technology, strategic partnering, outsourcing, inter-firm networks in the service and science-based industries, regional clusters, innovation and project management, and industrial relations.

Dr. Arnold Windeler is a Professor of Organizational Sociology at the Technische Universität Berlin. His research interests centre on issues of organizations, networks and social theory, especially structuration and praxis theory. His work has been published in journals including Organization Science and Organization Studies. He currently serves as a co-director of the doctoral program on 'Innovation Society Today: The Reflexive Creation of Novelty', financed by the German Research Foundation.

Dr. Gordon Müller-Seitz is a researcher at the Freie Universität Berlin, School of Business \& Economics, Department of Management. His research focuses upon interorganizational networks, open source software related phenomena, innovative technologies, project management, and professional service firms.

Dr. Knut Lange is a Lecturer in Innovation at the University of Surrey, Faculty of Business, Economics and Law. His research focuses upon interorganizational networks, innovation, institutions, comparative country studies, business models and family offices. 